\title{
Geographical patterns of excess mortality in Spain explained by two indices of deprivation
}

\author{
Joan Benach, Yutaka Yasui
}

\begin{abstract}
Study objective-To analyse the geographical patterns and the magnitude of the association between deprivation and mortality in Spain. To estimate the excess of mortality in more deprived areas of the country by region.

Design-Cross sectional ecological study using 1991 census variables and mortality data for 1987-1992.

Setting-2220 small areas in Spain.

Main results-A geographical gradient from north east to south west was shown by both mortality and deprivation levels in Spain. Two dimensions of deprivation (that is, Index 1 and Index 2) obtained by exploratory factor analysis using four census indicators were found to predict mortality: mortality over 65 years of age was more associated with Index 1, while mortality under 65 years of age was more associated with Index 2. Excess mortality in the most deprived areas accounted for about 35000 deaths.

Conclusions-Two indices of deprivation strongly predict mortality in two age groups. Excess number of deaths in the most deprived geographical areas account for $10 \%$ of total number of deaths annually. In Spain there is great potential for reducing mortality if the excess risk in more deprived areas fell to the level of the most affluent areas.
\end{abstract}

(F Epidemiol Community Health 1999;53:423-431)

Department of Experimental Sciences, Health and Technology, Occupational Health Unit, Pompeu Fabra University, Barcelona, Spain

J Benach

Cancer Prevention Research Program, Fred Hutchinson Cancer Research Center, Seattle, USA Y Yasui

Correspondence to: Dr J Benach, Department of Experimental Sciences, Health and Technology, Occupational Health Unit, Pompeu Fabra University, Carrer Dr Aiguader 80, 08003 Barcelona, Spain.

Accepted for publication 30 October 1998
Since the publication of the Black Report ${ }^{1}$ an increasing number of studies have shown that material deprivation indicators are important predictors of mortality inequalities. Strong positive associations between deprivation and mortality at small area levels have been mostly documented in England and Wales $^{2-5}$ and Scotland. ${ }^{5-8}$ In the analysis of 678 wards in the northern region of England, for example, age adjusted mortality rates in those aged $0-64$ in the $10 \%$ most favoured areas were about one third of the rates found in the $10 \%$ worst affected localities. ${ }^{2}$ Few studies have offered quantitative estimates of excess deaths in the most deprived areas. ${ }^{26}$ By the yardstick of the wards with the lowest mortality, the same study reported 930 excess deaths each year in the wards with the highest mortality. ${ }^{2}$

In contrast, in many other European countries, and particularly in the southern ones, research on deprivation and mortality inequalities at the national level using small area analysis is very limited. ${ }^{9}$ Additionally, many socioeconomic indicators are generally worse in the south compared with the north of Europe and the strength of the association between deprivation and mortality and their public health impact may be different. ${ }^{10}{ }^{11}$ Spain in the past decade has shown poorer deprivation indicators compared with more developed European countries: unemployment rates twice the European Union's average and higher percentages of poverty and illiteracy. ${ }^{12-14}$

Although there is no agreed upon definition for deprivation and how to measure it, ${ }^{15}{ }^{16}$ to best capture its multi-dimensionality, many different socioeconomic indicators have been used. The most commonly used composite indices have combined several correlated indicators into a single score. ${ }^{17} 18$ One of the drawbacks of using a single summary index is that some information can be hidden and therefore important aspects of deprivation may be lost. ${ }^{16}$ In this paper we used a different approach. By selecting four indicators from the 1991 Spanish census on the basis of the most relevant deprivation variables available and using exploratory factor analysis as a tool to tease out deprivation dimensions, we obtained two socioeconomic summary indices that were uncorrelated.

The aims of this study were: to analyse the geographical patterns and the magnitude of the relation between deprivation and mortality in 2220 small areas (hereafter called “zones") of Spain and to estimate the excess of mortality in deprived areas by 19 large regions (that is, Autonomous Communities). To our knowledge this study is the first nationallybased small area analysis of deprivation on mortality conducted in a southern European country.

\section{Methods}

Spain, a southern European country with almost 39 million inhabitants (1991 census data), is divided into 19 Autonomous Communities, 50 provinces and 8077 municipalities, which show a large diversity in their surface, population and socioeconomic variables. Using municipalities as the building blocks, and applying a Geographical Information System, 2220 geographical zones with at least 3500 inhabitants in each zone were constructed in a preliminary work. ${ }^{19}$ This geographical framework made it possible to obtain both socioeconomic variables from the census and aggregated mortality data in the small area level for the whole country that has been used in two previous descriptive studies. ${ }^{20} 21$ 
The number of deaths aggregated for 1987-1992 was available by age and zone from death certificates of the National Institute of Statistics of Spain. Total number of deaths for the period studied in Spain was 1947236. They varied from 58 to 5007 in the zones with less than 100000 people and from 1801 to 149694 in the zones over 100000 (including two zones with more than 1 million people). Only 9418 deaths could not be assigned to any zones. Similar small percentages of missing deaths $(0.1-0.6 \%)$ were found across the Autonomous Communities except in the Balearic and Canary islands and Ceuta and Melilla where the number ranged from $2 \%$ to $4 \%$. The populations in the 1991 census provided denominators for death rates in 1987-1992. To account for differences in age distribution across zones, a standardised mortality ratio for all deaths was computed for each zone by the indirect method. ${ }^{22}{ }^{23}$ A standardised mortality ratio value of a zone over (or under) 100 indicates more (or less) deaths than expected if the mortality in the zone was the same as that in Spain. Standardised mortality ratios for all deaths were calculated separately for two groups of age (0-64 and 65 or over). This cut off point has been commonly taken as the age limit to define premature mortality. ${ }^{2}{ }^{6}$

Socioeconomic and population data were drawn from the 1991 census. Variables were selected based on two points: (1) small area variables considered to reflect area specific socioeconomic deprivation; and (2) variables measured in a systematic uniform fashion such as those available from census. Based on the information available in the 1991 Spanish census, four deprivation indicators were selected following theoretical criteria. ${ }^{24}{ }^{25}$ Unemployment (percentage of unemployed in the population aged 15 to 64 years) reflects the lack of income and material resources and vital and personal insecurity. Illiteracy (percentage of illiterate people in the population over age 10) reflects states of extreme lack of education. Persons considered illiterate include those who fell into one of two categories: lack of skills to write or read or those without any formal education. Social class (the number of persons with unskilled occupations divided by all people who ever worked) has been considered to be a fundamental element for explaining the relation between socioeconomic factors and health. Overcrowding (percentage of households with more than one person per room) refers to the lack of material resources. The first three indicators were moderately correlated (Pearson correlation coefficients ranged from 0.42 to 0.57 ) while overcrowding showed lower correlations (0.11 to 0.36$)$ with the other three. Using the four census deprivation indicators and applying exploratory factor analysis method with varimax rotation, ${ }^{26}$ two socioeconomic dimensions (that is, Index 1 and Index 2) were identified that were uncorrelated with each other. Index 1 explained $47.6 \%$ of the variation of the four indicators, while Index 2 added $29.3 \%$ more accounting for a total of $76.9 \%$ of the variation. For Index 1, unemployment, illiteracy, and low social class showed high factor loadings $(0.70,0.82$, and 0.85$)$ while for overcrowding it was very low (0.08). For Index 2 , the factor loading was very high for overcrowding (0.95), low for unemployment and illiteracy, (0.44 and 0.23) and nearly zero for low social class $(-0.09)$. Deprivation scores for both indices were computed for each zone by computing factor scores. ${ }^{26}$ Increasing scores in each index indicate greater levels of deprivation. Those scores were then categorised into quintiles.

Our analysis of the association between deprivation and mortality used exploratory tools such as descriptive tables and small area choropleth maps. Geographical distributions of each deprivation index and standardised mortality ratios in quintiles were examined visually using maps for each age group. Medians and upper/lower quartiles of standardised mortality ratios and those of deprivation indices were compared by the Autonomous Community level. The gradient of the association was then assessed by comparing standardised mortality ratios by quintiles of each deprivation index.

Table 1 Population size, number of zones, socioeconomic indicators (1991 census), and the summary distribution (quartiles) of deprivation indices (grouped by quintiles of factor scores from $1=$ best to $5=$ worst) and SMRs (0-64 and 65+) within each of the 19 autonomous communities of Spain

\begin{tabular}{|c|c|c|c|c|c|c|c|c|c|}
\hline \multirow{2}{*}{$\begin{array}{l}\text { Autonomous } \\
\text { communities }\end{array}$} & \multirow[b]{2}{*}{ Population (\%) } & \multirow{2}{*}{$\begin{array}{l}\text { Number of } \\
\text { zones (\%) }\end{array}$} & \multirow{2}{*}{$\begin{array}{l}\text { Percentage } \\
\text { unemployed (no } \\
\text { order) }\end{array}$} & \multirow{2}{*}{$\begin{array}{l}\text { Percentage } \\
\text { illiteracy (no } \\
\text { order) }\end{array}$} & \multirow{2}{*}{$\begin{array}{l}\text { Percentage } \\
\text { overcrowded (no } \\
\text { order) }\end{array}$} & \multirow{2}{*}{$\begin{array}{l}\text { Percentage low } \\
\text { social class (no } \\
\text { order) }\end{array}$} & \multicolumn{3}{|c|}{ Deprivation index 1} \\
\hline & & & & & & & $25 \%$ & $50 \%$ & $75 \%$ \\
\hline Andalusia & $6940522(17.85)$ & 405 (18.24) & $28.9(4)$ & $8.7(1)$ & $13.2(6)$ & $59(1)$ & 4 & 5 & 5 \\
\hline Catalonia & $6059494(15.59)$ & $290(13.06)$ & $11.3(17)$ & $2(13)$ & $9.6(11)$ & $45.6(8)$ & 1 & 2 & 3 \\
\hline Madrid & 4947555 (12.73) & $68(3.06)$ & $12.4(16)$ & $2.1(12)$ & $10.3(7)$ & $40.7(12)$ & 1 & 2 & 3 \\
\hline Valencia & $3857234(9.92)$ & $208(9.37)$ & $16.3(8)$ & $2.9(9)$ & $9.2(14)$ & $53.9(4)$ & 3 & 4 & 4 \\
\hline Galicia & $2731669(7.03)$ & $219(9.86)$ & $14.2(13)$ & $3.4(8)$ & $13.7(5)$ & $38.6(14)$ & 1 & 2 & 3 \\
\hline C.Leon & $2545926(6.55)$ & $241(10.86)$ & $14.7(12)$ & $1.3(14)$ & 7.4 (15) & $37.1(16)$ & 1 & 2 & 3 \\
\hline Basque country & $2104041(5.41)$ & $103(4.64)$ & $17.1(6)$ & $1.2(15)$ & $9.6(12)$ & $48.5(7)$ & 2 & 3 & 3 \\
\hline C.Mancha & $1658446(4.26)$ & $170(7.66)$ & $13.2(15)$ & $7(5)$ & $7.2(16)$ & $52.7(5)$ & 4 & 4 & 5 \\
\hline Canary islands & $1493784(3.84)$ & $70(3.15)$ & $27(5)$ & $5(7)$ & $29.1(3)$ & 39.9 (13) & 1 & 3 & 3 \\
\hline Aragón & $1188817(3.06)$ & $84(3.78)$ & $9.3(19)$ & $2.2(11)$ & $4.6(19)$ & $40.7(11)$ & 1 & 2 & 3 \\
\hline Asturias & $1093937(2.81)$ & $47(2.12)$ & $16(11)$ & $1(17)$ & $10.3(8)$ & $37.2(15)$ & 1 & 1 & 2 \\
\hline Extremadura & $1061852(2.73)$ & $119(5.36)$ & $30.3(1)$ & $7.7(3)$ & $14.1(4)$ & $54.7(3)$ & 4 & 5 & 5 \\
\hline Murcia & $1045601(2.69)$ & $39(1.76)$ & $16.2(9)$ & $5.3(6)$ & $11(10)$ & $58.2(2)$ & 4 & 4 & 5 \\
\hline Balearic islands & $709138(1.82)$ & $44(1.98)$ & $16.1(10)$ & $2.4(10)$ & $9.2(13)$ & $35.4(17)$ & 1 & 2 & 3 \\
\hline Cantabria & $527326(1.36)$ & $41(1.85)$ & $16.4(7)$ & $0.6(19)$ & $11.7(9)$ & $41.6(10)$ & 1 & 2 & 2 \\
\hline Navarre & $519277(1.33)$ & $48(2.16)$ & $14.2(14)$ & $1(18)$ & $6.3(17)$ & $50.2(6)$ & 2 & 3 & 3 \\
\hline Rioja & $263434(0.68)$ & $23(1.04)$ & $11.2(18)$ & $1.1(16)$ & $5.5(18)$ & $45.6(9)$ & 2 & 2 & 3 \\
\hline Ceuta & $67615(0.17)$ & $1(0.04)$ & $30.1(2)$ & $7(4)$ & $29.9(2)$ & $24.4(19)$ & 2 & 2 & 2 \\
\hline Melilla & $56600(0.15)$ & $1(0.04)$ & 29.1 (3) & $8.2(2)$ & $30.7(1)$ & $26.6(18)$ & 2 & 2 & 2 \\
\hline Spain & $38872268(100)$ & $2220(100)$ & 16.12 & 3.05 & 9.81 & 47.1 & 2 & 3 & 4 \\
\hline
\end{tabular}


After these exploratory steps, we confirmed the gradient by using Poisson regression models with random effects. ${ }^{27}$ The number of excess deaths were computed based on the Poisson regression model by hypothetically reducing the level of deprivation (one or both indices) of each zone to the lowest quintile and computing the reduction in model fitted expected number of deaths. The use of quintiles rather than deciles allowed us to get a more stable estimation of deprivation effects. Models rather than crude mortality rates were used because we considered two indices of deprivation: to control for the effects of one deprivation index when estimating the effects of the other deprivation index.

\section{Results}

Table 1 shows a summary of demographic, socioeconomic, and mortality indicators of zones by Autonomous Communities ranked by the population level. Differences in deprivation indices and mortality were seen across Autonomous Communities. The worst deprivation indices and mortality were seen in two Autonomous Communities located in the south and south west (that is, Andalucia and Extremadura) and the cities of Ceuta and Melilla, while most north east Autonomous Communities (for example, Navarre, Catalonia, Rioja, and Aragón) had better scores. Standardised mortality ratios in the people aged $0-64$ tended to be more associated to Index 2 while standardised mortality ratios for the older age group (65 or over) were more associated to Index 1. For example, two south eastern Autonomous Communities (that is, Valencia and Murcia) showed high values of standardised mortality ratios in the older group of age (65 or over) and Index 1, but lower values of standardised mortality ratios in the people aged 0-64 and Index 2. Two Autonomous Communities located in the north west of the country (that is, Galicia and Asturias) showed high values of standardised mortality ratios in the people aged $0-64$ and Index 2 but lower values of standardised mortality ratios in the people aged 65 or over and

Table 1 (Continued)

\begin{tabular}{|c|c|c|c|c|c|c|c|c|}
\hline \multicolumn{3}{|c|}{ Deprivation index 2} & \multicolumn{3}{|c|}{ SMRs 0-64 } & \multicolumn{3}{|c|}{ SMRs 65+ } \\
\hline $25 \%$ & $50 \%$ & $75 \%$ & $25 \%$ & $50 \%$ & $75 \%$ & $25 \%$ & $50 \%$ & $75 \%$ \\
\hline 3 & 4 & 5 & 86 & 99 & 110 & 102 & 112 & 122 \\
\hline 1 & 3 & 4 & 80 & 91 & 100 & 90 & 97 & 103 \\
\hline 3 & 3 & 4 & 78 & 87 & 98 & 90 & 100 & 116 \\
\hline 1 & 2 & 3 & 86 & 95 & 105 & 107 & 113 & 120 \\
\hline 3 & 4 & 5 & 93 & 104 & 113 & 90 & 97 & 103 \\
\hline 2 & 2 & 3 & 79 & 91 & 102 & 79 & 86 & 92 \\
\hline 2 & 3 & 3 & 91 & 99 & 108 & 90 & 96 & 104 \\
\hline 1 & 2 & 2 & 76 & 84 & 93 & 90 & 98 & 110 \\
\hline 5 & 5 & 5 & 87 & 98 & 113 & 91 & 101 & 112 \\
\hline 1 & 1 & 2 & 77 & 88 & 95 & 82 & 89 & 98 \\
\hline 3 & 3 & 4 & 104 & 113 & 120 & 97 & 102 & 105 \\
\hline 3 & 4 & 5 & 92 & 100 & 111 & 98 & 105 & 112 \\
\hline 2 & 3 & 4 & 87 & 93 & 100 & 105 & 110 & 121 \\
\hline 2 & 3 & 4 & 90 & 99 & 108 & 99 & 104 & 110 \\
\hline 3 & 4 & 4 & 87 & 97 & 109 & 87 & 93 & 99 \\
\hline 1 & 1 & 2 & 77 & 85 & 93 & 83 & 90 & 95 \\
\hline 1 & 1 & 1 & 84 & 94 & 99 & 89 & 96 & 102 \\
\hline 5 & 5 & 5 & - & 121 & - & - & 118 & - \\
\hline 5 & 5 & 5 & - & 119 & - & - & 112 & - \\
\hline 2 & 3 & 4 & 84 & 95 & 106 & 90 & 100 & 111 \\
\hline
\end{tabular}

KEY POINTS

- Geographical patterns of excess mortality in Spain are associated with two indices of deprivation.

- Increasing levels of deprivation indices are differently associated with mortality for two age groups (0-64 and 65 or over).

- Excess mortality in the more deprived areas account for about 35000 annual deaths. A higher proportion is found in southern regions.

- There is great potential for reducing mortality if the excess deaths in more deprived areas fell to the level of the most affluent areas.

- Small area studies are a valuable tool to analyse and to pinpoint areas with higher mortality.

Index 1. Large variations in standardised mortality ratios were observed in some Autonomous Communities. Canary Islands showed a large interquartile range of standardised mortality ratios for the younger group of age, while Madrid had a large interquartile range of standardised mortality ratios for the older age group.

Maps displayed geographical inequalities across small areas of Spain. An overall worsening pattern for both mortality and deprivation indices from the north east to the south west was found. Nevertheless, depending on the index and the age group selected, two different geographical patterns were observed. Firstly, higher scores of Index 1 were mainly shown in the south of the country (fig 1A) in parallel to higher mortality for the people aged 65 or over (fig 1D). Secondly, higher scores of Index 2 were mainly shown in the north west and south west of Spain (fig 1B) in parallel to higher mortality shown for the people aged 0-64 (fig 1C).

Table 2 shows the association between deprivation and mortality by quintiles of Index 1 and Index 2 separately. Consistent with the results obtained in table 1 and figure 1 , increasing scores of both deprivation indices were associated with mortality by age group according to the patterns described above. However, while Index 1 only showed a gradient with standardised mortality ratios for the age group 65 or over, Index 2 showed gradients in both groups of age although the gradient of the association was steeper in the age group 0-64.

Estimates and confidence intervals of the excess mortality (percentage) relative to the lowest deprivation quintile were plotted against both deprivation indices by age group. The positive association of excess mortality with Index 1 was confirmed in the age group 65 or over, while in the age group 0-64 no gradient was found (fig 2A). The most deprived group had $13.2 \%$ excess of deaths in comparison with the least deprived group. Index 2 showed increasing percentages of excess mortality in both age groups, although the gradient was steeper in the younger group 

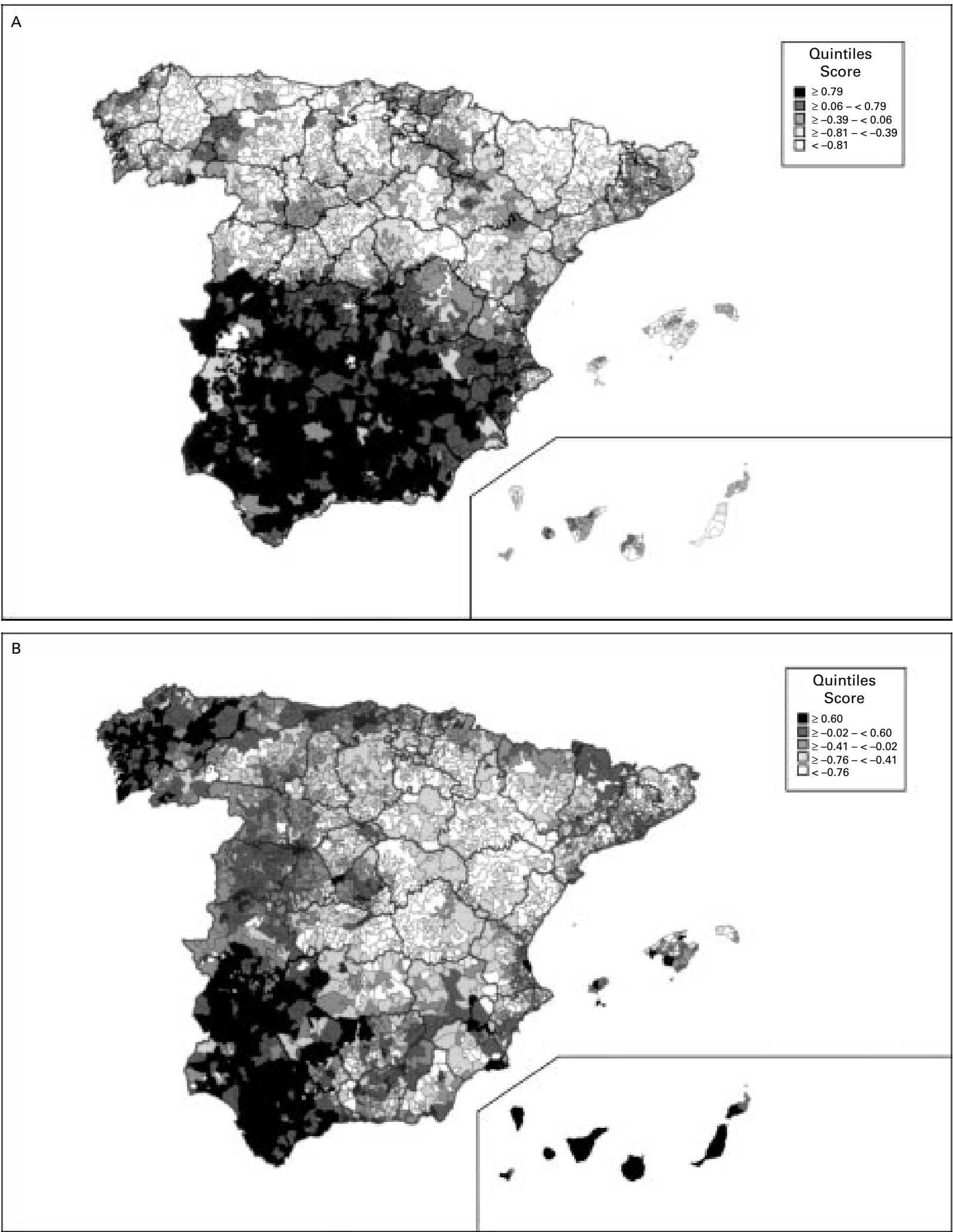

Figure 1 (A) Deprivation Index 1 in Spain 1991 for 2220 zones. (B) Deprivation Index 2 in Spain 1991 for 2220 zones. (C) Standardised mortality ratios 0-64 in Spain 1987-92 for 2220 zones. (D) Standardised mortality ratios 65 or over in Spain $1987-92$ for 2220 zones.

(fig 2B). Estimates of the excess annual deaths by the Autonomous Community are shown in table 3. Total annual excess of deaths was estimated to be about 35000 people in Spain. As expected the five most populated Autonomous Communities (that is, Andalucia, Catalonia,
Valencia, Galicia, and Madrid) showed higher number of excess deaths. However, Andalucia and Extremadura located in the south and south west and comprising approximately one fifth of the population accounted for almost one third (10 450) of the total excess deaths. 

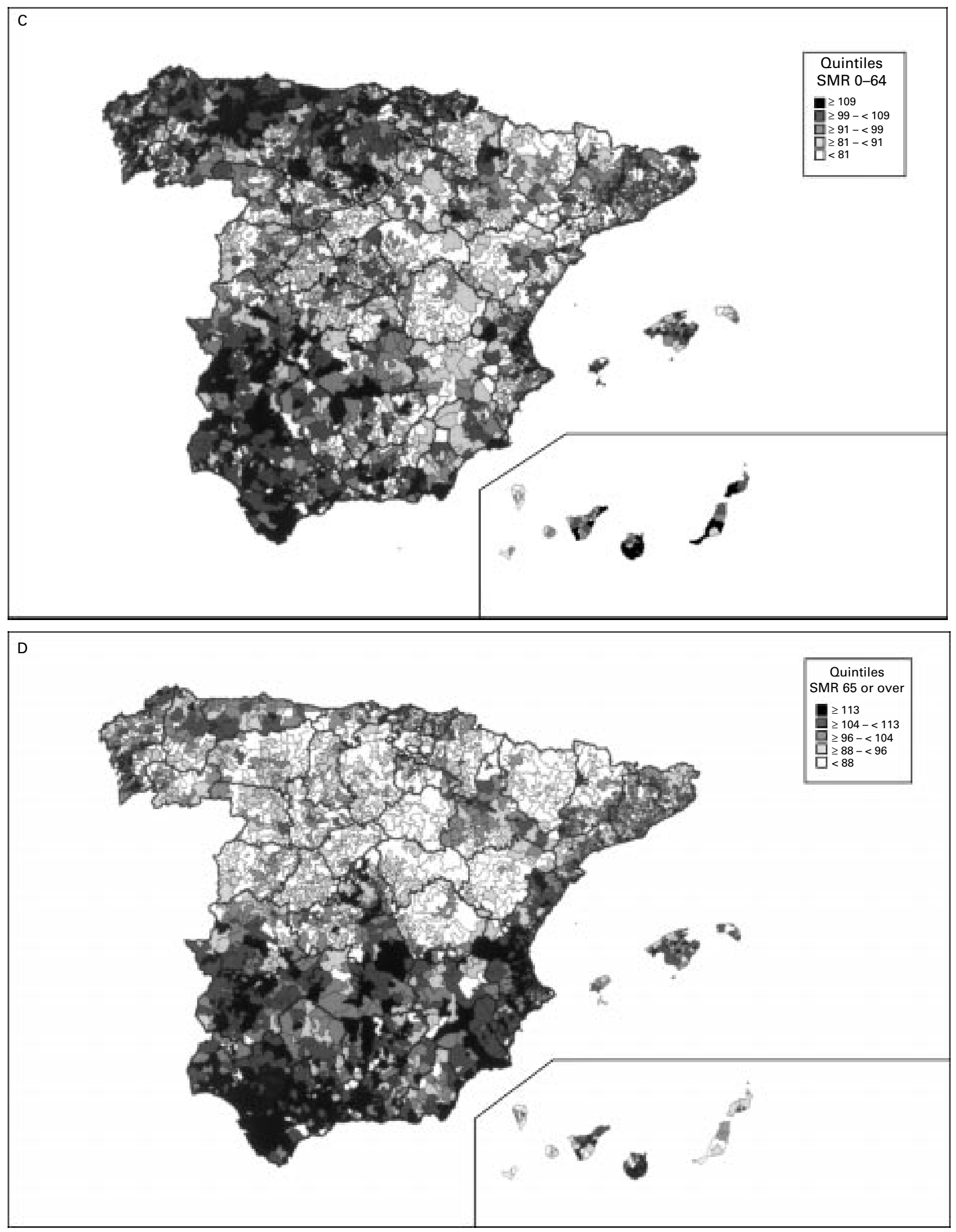

Figure 1 (Continued)

Relative to their population size, the Autonomous Communities of Valencia and Murcia showed high excess numbers of deaths in the age group 65 or over, while Asturias and Galicia had high excess mortality in the age group $0-64$.

\section{Discussion}

Several editorials have emphasised the public health impact resulting from the excess mortality in the more deprived population groups of the United Kingdom and the United States and the need to tackle health inequalities. ${ }^{29-31}$ 
Table 2 Distribution of 1991 census socioeconomic indicators (median percentages or otherwise indicated) in 2220 zones in Spain in 1991 and SMRs 1987-92 by age level by quintiles of deprivation indices in Spain

\begin{tabular}{|c|c|c|c|c|c|c|c|}
\hline & $\begin{array}{l}\text { People } \\
\text { unemployed }\end{array}$ & $\begin{array}{l}\text { People } \\
\text { illiterate }\end{array}$ & $\begin{array}{l}\text { People of } \\
\text { low social } \\
\text { class }\end{array}$ & $\begin{array}{l}\text { Households } \\
\text { overcrowded }\end{array}$ & $\begin{array}{l}\text { Total } \\
\text { population } \\
\times 10^{5}(\%)\end{array}$ & $\begin{array}{l}\text { SMRs } \\
0-64\end{array}$ & $\begin{array}{l}\text { SMRs } \\
65+\end{array}$ \\
\hline \multicolumn{8}{|c|}{ Zones by deprivation level measured by deprivation index 1} \\
\hline Most deprived fifth & 30.3 & 9.3 & 62.2 & 11.0 & $35(8.9)$ & 96 & 107 \\
\hline Second fifth & 17.9 & 4.9 & 55.3 & 9.6 & $53(13.5)$ & 94 & 105 \\
\hline Third fifth & 16.1 & 2.7 & 48.8 & 9.8 & $68(17.4)$ & 95 & 99 \\
\hline Fourth fifth & 13.9 & 2.0 & 41.0 & 9.2 & $93(23.8)$ & 96 & 96 \\
\hline Least deprived fifth & 11.9 & 1.4 & 30.0 & 9.6 & $141(36.3)$ & 93 & 92 \\
\hline Index 1 Spain & 16.1 & 3.0 & 47.1 & 9.8 & $388(100)$ & 95 & 100 \\
\hline \multicolumn{8}{|c|}{ Zones by deprivation level measured by deprivation index 2} \\
\hline Most deprived fifth & 25.0 & 5.6 & 46.1 & 20.8 & $102(26.3)$ & 102 & 107 \\
\hline Second fifth & 17.3 & 3.1 & 43.8 & 12.9 & $146(37.4)$ & 98 & 100 \\
\hline Third fifth & 16.5 & 2.4 & 44.4 & 9.5 & $63(16.2)$ & 96 & 100 \\
\hline Fourth fifth & 14.7 & 2.5 & 47.6 & 7.6 & $48(12.3)$ & 91 & 97 \\
\hline Least deprived fifth & 11.3 & 2.6 & 51.4 & 5.4 & $30(7.7)$ & 88 & 97 \\
\hline Index 2 Spain & 16.1 & 3.0 & 47.1 & 9.8 & $388(100)$ & 95 & 100 \\
\hline
\end{tabular}

Although many studies have been conducted in the United Kingdom, Sweden and the Netherlands, little has been done to assess the effects of deprivation on mortality in other European countries. This investigation has shown: (1) the association and its gradient between deprivation and mortality in small areas of Spain and (2) estimated the levels of excess deaths by Autonomous Communities. The level of deprivation and excess mortality differed substantially within the country. A striking example was found in Andalucia, which showed much higher levels of deprivation: with only $18 \%$ of the nation's population this Autonomous Community accounted for almost $30 \%$ of the unemployed and one third of the illiterate.
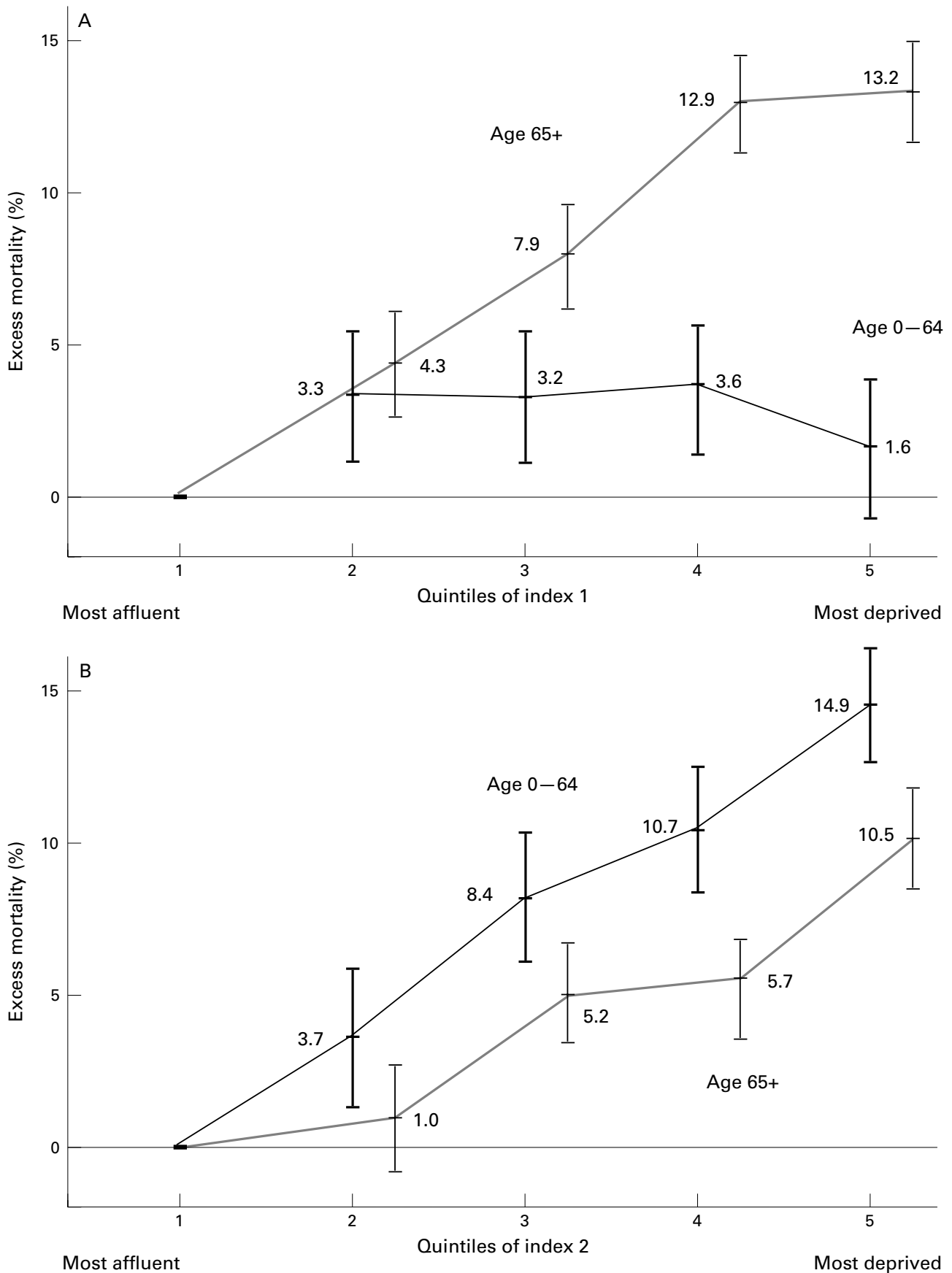

Figure 2 (A) Excess mortality (percentage and 95\% confidence intervals) by quintiles of Index 1 for age 0-64 and 65 or over. (B) Excess mortality (percentage and 95\% confidence intervals) by quintiles of Index 2 for age 0-64 and 65 or over. 
Table 3 Excess annual of deaths by two deprivation indices and average annual number of deaths (1987-92) in 19 autonomous communities in Spain by group of age

\begin{tabular}{|c|c|c|c|c|c|c|c|c|c|}
\hline \multirow{2}{*}{$\begin{array}{l}\text { Autonomous } \\
\text { communities }\end{array}$} & \multicolumn{3}{|c|}{$0-64$ years of age } & \multirow[b]{2}{*}{ Deaths (n) } & \multicolumn{3}{|c|}{$65+$ years of age } & \multirow[b]{2}{*}{ Deaths (n) } & \multirow{2}{*}{$\begin{array}{l}\text { Total } \\
\text { excess } \\
\text { deaths }\end{array}$} \\
\hline & Index 1 & Index 2 & Total & & Index 1 & Index 2 & Total & & \\
\hline Andalusia & 300 & 1770 & 2030 & 13926 & 3540 & 3270 & 6550 & 40510 & 8580 \\
\hline Catalonia & 230 & 1220 & 1430 & 12239 & 1520 & 2070 & 3500 & 38526 & 4930 \\
\hline Valencia & 170 & 630 & 790 & 7851 & 1790 & 1030 & 2760 & 25693 & 3550 \\
\hline Galicia & 130 & 630 & 740 & 6006 & 890 & 1340 & 2180 & 20891 & 2920 \\
\hline Madrid & 60 & 1040 & 1090 & 9394 & 230 & 1460 & 1680 & 24417 & 2770 \\
\hline C.Mancha & 80 & 150 & 220 & 2958 & 1280 & 280 & 1540 & 12641 & 1760 \\
\hline C.Leon & 90 & 340 & 420 & 4892 & 640 & 710 & 1330 & 18708 & 1750 \\
\hline Extremadura & 50 & 270 & 320 & 2200 & 840 & 640 & 1420 & 8078 & 1740 \\
\hline Canary islands & 40 & 460 & 490 & 3077 & 250 & 730 & 950 & 6964 & 1440 \\
\hline Basque Country & 90 & 370 & 460 & 4448 & 470 & 520 & 970 & 11548 & 1430 \\
\hline Murcia & 60 & 190 & 240 & 1982 & 540 & 320 & 830 & 6205 & 1070 \\
\hline Asturias & 60 & 220 & 270 & 2608 & 300 & 440 & 730 & 8546 & 1000 \\
\hline Aragón & 60 & 60 & 120 & 2300 & 410 & 70 & 480 & 9206 & 600 \\
\hline Balearic islands & 20 & 150 & 170 & 1566 & 120 & 260 & 370 & 5033 & 540 \\
\hline Cantabria & 20 & 110 & 130 & 1066 & 80 & 220 & 290 & 3562 & 420 \\
\hline Navarre & 20 & 50 & 60 & 914 & 160 & 80 & 250 & 3339 & 310 \\
\hline Rioja & 20 & 10 & 30 & 518 & 100 & 10 & 110 & 1890 & 140 \\
\hline Ceuta & 10 & 20 & 30 & 151 & 10 & 30 & 40 & 319 & 70 \\
\hline Melilla & 10 & 20 & 20 & 124 & 10 & 20 & 40 & 245 & 60 \\
\hline Spain & 1490 & 7710 & 9060 & 469316 & 13190 & 13500 & 26030 & 1477920 & 35090 \\
\hline
\end{tabular}

Evidence from our study supports the idea that the health of people residing in such deprived areas is unfavourable. This must be recognised and tackled as a major public health problem.

DEPRIVATION INDICES AS PREDICTORS OF AGE RELATED MORTALITY

Exploratory factor analysis allowed for reduction of redundancy in the four indicators and produced two uncorrelated deprivation indices with reasonable levels of societal interpretation. Index 1 basically captured the meaning derived from unemployment, illiteracy, and low social class while index 2 basically referred to overcrowding. Using two dimensions rather than each of the four indicators was useful: (1) to clearly contrast the two types of deprivation in relation to mortality, which is not possible if analysed using each indicator and (2) to concisely convey our main findings instead of presenting four different analyses. We found differential gradients between those indices and mortality indicators in two age groups. Index 1 predicted mortality for the older age group (65 or over) but not for the younger group (under 65). In contrast, Index 2 predicted mortality for both age groups although in people aged 0-64 the gradient was steeper. Reasons for those findings are unclear. Index 1 and Index 2 may reflect some rural and urban socioeconomic characteristics, which are likely to be related to age. However, as rural-urban differences were not studied in this paper, labelling the two indices with two clear cut notions such as "rural poverty" for Index 1 and "urban poverty" for Index 2 would be an over-interpretation of our results. Although for some specific geographical areas it would be possible to speculate on some factors, explanations for the whole country should be provided by further studies focusing on causes of death at the small area level within specific regions of the country. Standardised mortality ratios for 65 or over in the most deprived fifth of Index 1 and Index 2 were around 13\% and 10.5\% higher, respectively, than those in the least deprived fifth. Standardised mortality ratios for the under 65 in the most deprived fifth of Index
2 were around $15 \%$ higher than those in the least deprived fifth. The mortality gradient by deprivation levels was smaller than those found in other studies conducted in the United Kingdom ${ }^{4}{ }^{7}$ but similar to a study carried out in the Netherlands. ${ }^{9}$ Reasons for these differences are not clear. As the north of England and Scotland have shown higher mortality rates within Europe, ${ }^{32} 33$ and high death rates are often related to large socioeconomic differences, they might reflect real variations across the countries. Alternatively, deprivation indices might have different social meanings and effects between and within European countries. A study suggested that unemployment in Spain might be less stressful in southern regions where this condition is a "usual" state, while the social differentiation that stigmatises those unemployed in northern areas with economic crisis might be greater. ${ }^{34}$ In addition, other factors might lead to underestimate the association between deprivation and mortality in Spain. For example, some of the zones studied were large urban areas in some of which mortality inequalities have been reported..$^{35} 36$

GEOGRAPHICAL PATTERNS IN DEPRIVATION RELATED MORTALITY

Use of choropleth maps enabled us to examine the geographical distribution of deprivation and mortality across the country at the small area level. Despite some shortcomings (for example, attention may be concentrated in sparsely populated areas), ${ }^{37}$ this method of visualising information is informative and the most widely approach used in geographical epidemiology. Higher levels of deprivation in Index 1 and higher mortality levels for the 65 and over age group matched in the south of Spain. Higher levels of deprivation in Index 2 appeared in the north west and south west of Spain predicting mortality for people aged $0-64$. As causes of death were not studied explanations of those spatial patterns are not straightforward. Whether material or individual circumstances cause mortality differences may be debated. Both deprivation indices may predict mortality by reflecting 
aggregate individual deprivation or socioenvironmental deprivation. Research has not shown consistent results on whether or not area characteristics have an independent effect on mortality. ${ }^{38} 39$ For example, evidence of the deleterious effects of overcrowded household conditions is mixed. In some studies overcrowding had substantial negative effects ${ }^{40}$ on mortality while there was no evidence in other studies. ${ }^{41}$ Although results might reflect differences in the methods used they could also indicate differences in the meaning of overcrowding for different areas. On the other hand, potential buffering effects on health of social networks, social support, and social cohesion reported by some studies ${ }^{42}$ have not been investigated, and the direction and magnitude of these possible effects is uncertain. All these explanations are possible but they do not contradict the fact that differential mortality effects are predicted by both deprivation indices. This research analysed the association between deprivation and mortality indicators but other mediating factors (for example, social deprivation, individual experience, individual behaviours or psychobiological factors) that lead to death were not investigated. Future studies that investigate in detail causes of death at the small area level should provide more specific answers to explain those associations observed here.

SMALL AREA ANALYSIS, EXCESS OF DEATHS AND HEALTH POLICY INTERVENTIONS

In Spain two major problems in existing health related data sources hinder the possibility to study nationally-based mortality inequalities at the individual level: (1) the lack of valid data in recording occupation on the death certificates, and (2) the existence of legislation that restricts the use of data on individual people making impossible its linkage with census information. ${ }^{20}$ The 1991 Spanish Census is the only source of reliable and comparable socioeconomic data with complete coverage of Spain's population at the small area level. Illiteracy is the only one of the four selected deprivation indicators that has not been used as often in similar small area studies. It was included because education is a socioeconomic indicator often used in inequality research, ${ }^{43}$ and in Spain education is a useful indicator to predict small area mortality inequalities. ${ }^{35} 36$ Under the circumstances without a reliable individual database, public health researchers and policy makers could benefit from this approach. In Spain, as perhaps in other European countries, the study of mortality inequalities in the small area level overcomes the absence of socioeconomic data at the individual level. This study estimated excess of deaths at about $10 \%$ of total annual mortality deaths. Although causes of geographical patterns and excess mortality are not clear, those findings may have important implications from social and health policy perspectives.

Historical experience shows that ignoring mortality inequalities will not make them disappear or decrease. If more deprived zones are associated with poorer mortality indicators, efforts to correct those inequalities should involve a positive discrimination of resources. Estimate of excess of deaths in those political areas should help political decision makers to implement decisions to reduce health inequalities. In Spain there is great potential for reducing mortality if the excess risk in more deprived areas were to fall to the level of the most affluent areas.

This paper is partially based on the first author's doctoral dissertation at Johns Hopkins School of Public Health directed by V Navarro. We are grateful to $\mathrm{H}$ Chamizo and $\mathrm{M}^{\mathrm{a}} \mathrm{D}$ García for their help in making the geographical framework used in this research, and to C Borrell and $\mathrm{M}^{\mathrm{a}}$ I Pasarín for their assistance in preparing the data set used. The authors also thank Richard Wilkinson for his helpful comments on an earlier version of this paper.

Conflicts of interest: none.

1 Townsend P, Davidson N, eds. Inequalities in health: the Black Report. Harmondsworth: Penguin, 1988.

2 Townsend P, Phillimore P, Beattie A. Health and deprivation. Inequality and the North. London: Croom Helm, 1988.

3 Eames M, Ben-Shlomo Y, Marmot MG. Social deprivation and premature mortality: regional comparison across Eng-
and and. BMF 1993;307:1097-102.

4 Phillimore P, Beattie A, Townsend P. Widening inequality of health in northern England, 1981-91. BMF 1994;308: $1125-8$

5 Carstairs V, Morris R. Deprivation: explaining differences in mortality between Scotland and England and Wales. BMF 1989;299:886-9.

6 Carstairs V, Morris R. Deprivation and health in Scotland. Aberdeen: Aberdeen University Press, 1991

7 McLoone P, Boddy FA. Deprivation and mortality in Scotland, 1981 and 1991. BMf 1994;309:1465-70.

8 McCarron PG, Davey Smith G, Womersley JJ. Deprivation and mortality in Glasglow from 1980 to 1992 . BMF 1994; 309:1481-2.

9 Mackenbach JP, Kunst AE, Looman CWN. Cultural and economic determinants of geographical mortality patterns in The Netherlands. $f$ Epidemiol Community Health in The Nether

10 Lemkow L. Socio-economic status differences in health. Soc Sci Med 1986;22:1257-62.

11 Ramis-Juan O, Sokov V. Social health inequalities in south European countries: it is a different problem? In: Fox J, ed. Health inequalities in European countries. Aldershot: Gower, 1989:301-14.

12 Organization for Economical Cooperation and Development. Employment outlook. Paris: OECD, 1994.

13 Organization for Economical Cooperation and Development. Education at a glance. Paris: OECD, 1992.

14 Eurostat. Poverty statistics in the late 1980s. Luxembourg: Office for Official Publications of the EC, 1994

15 Gordon D. Census based deprivation indices: their weighting and validation. $f$ Epidemiol Community Health 1995;49 (suppl 2):S39-44.

16 Folwell K. Single measures of deprivation. $\mathcal{F}$ Epidemiol ComFolwell K. Single measures of dept

17 Morris R, Carstairs V. Which deprivation? A comparison of Morris R, Carstairs V. Which deprivation? A comparison of
selected deprivation indexes. F Public Health Med 1991;13: 318-26.

18 Carstairs V. Deprivation indices: their interpretation and use in relation to health. $\mathcal{F}$ Epidemiol Community Health 1995;49:S3-8.

19 Benach J, García MD, Donado-Campos J. GIS for mapping mortality inequalities in Spain and its socioeconomic determinants. Constructing regions using small areas. International Symposium on Computer Mapping in Epidemiology and Environmental Health. 1995. Tampa: Book of Proceedings, 1997:314-22.

20 Navarro V, Benach J, eds. Desigualdades sociales en salud en España. Madrid: Ministerio de Sanidad y Consumo, 1996.

21 Benach J, Borrell C, García MD, et al. Desigualdades sociales en mortalidad en áreas pequeñas en España. Sociedad Española de Salud Pública y Administración Sanitaria. Informe SESPAS: La salud pública y el futuro del Sanitaria. Informe SESPAS: La salud publica y el fut

22 Mantel N, Stark CR. Computation of indirect-adjusted rates in the presence of confounding. Biometrics 1968; 24:997-1005

23 Clayton D, Kaldor J. Empirical Bayes estimates of age-standardized relative risks for use in disease mapping. Biometrics 1987;43:671-81.

24 Amick III BC, Levine S, Tarlov AR, et al, eds. Society and Health. New York: Oxford University Press, 1995.

25 Krieger N, Williams DR, Moss NE. Measuring social class in US public health research: concepts, methodologies and guidelines. Annu Rev Public Health 1997;18:341-78.

26 Morrison DF. Multivariate statistical methods. 2nd ed. New York: McGraw Hill, 1976.

27 Clayton D, Bernardinelli L. Bayesian methods for mapping disease risk. In: Elliott P, Cuzick J, English D, et al, eds. Geographical and environmental epidemiology: methods for small area studies. Oxford: Oxford University Press, small area studi $205-20$ 
28 Wilkinson RG. Divided we fall. BMf 1994;308:1113-14. 29 Angell M. Privilege and health-what is the connection? Angell M. Privilege and healt

30 Wilkinson RG "Variations" in health BMF 1995:311:11778 .

31 Anonymous. Health inequality: the UK's biggest issue. Lancet 1997;349:1185.

32 Mackenbach JP, Kunst AE, Cavelaars AE, et al. Socioeconomic inequalities in morbidity and mortality in western Europe. The EU Working Group on Socioeconomic Inequalities in Health. Lancet 1997;349:1655-9.

33 Holland WW, ed. European Community atlas of "avoidable death". 2nd ed. Oxford: Oxford University Press, 1991.

34 Benavides FG, García AM, Sáez-Lloret I, et al. Unemployment and health in Spain. Eur f Public Health 1994;4:10

35 Borrell C, Arias A. Socio-economic factors and mortality in urban settings: the case of Barcelona (Spain). $f$ Epidemio Community Health 1995;49:460-5.

36 Arias A, Rebagliato M, Palumbo MA, et al. Desigualdades en salud en Barcelona y Valencia. Med Clin (Barc) 1993;100:281-7.
37 Dorling D. Visualizing the 1991 Census. In: Openshaw S, ed. Census user's handbook. Cambridge: GeoInformation International, 1995:167-211.

38 Slogett A, Joshi H. Higher mortality in deprived areas: com-munity or personal disadvantage? BMf 1994;309: $1470-4$

39 Ben-Shlomo Y, White IR, Marmot M. Does the variation in the socioeconomic characteristics of an area affect mortality? BMF 1996;312:1013-14

40 Gove W, Hughes M, Galle O. Overcrowding in the home: A empirical investigation of its possible pathological consequences. Am Soc Rev 1979;44:59-80.

41 Factor R, Waldron I. Contemporary population densities and human health. Nature 1973;243:381-4.

42 Wilkinson RG. Unhealthy societies. The afflictions of inequality. London: Routledge, 1996.

43 Blane D, White I, Morris J. Education, social circumstances and mortality. In: Blane D, Brunner E, Wilkinson R, eds. 171-87. 